\title{
Facades of Tall Buildings - State of the Art
}

\author{
Umarani Gunasekaran (Corresponding author) \\ Associate Professor, Department of Civil Engineering \\ Anna University, Chennai, India - 600025 \\ Tel: 91-44-2235-7409 E-mail: umaraniguna@yahoo.com \\ Premalatha E \\ M.S.(By Research) Scholar, Department of Civil Engineering \\ Anna University, Chennai, India - 600025 \\ Tel: 91-994-120-3532 E-mail: prema_premi34@hotmail.com
}

\author{
Aruna Malini. T.P \\ M.E Student, Department of Civil Engineering \\ Anna University, Chennai, India - 600025 \\ Tel: 91-978-824-2651_E-mail: sriaruna_civil@yahoo.co.in
}

\begin{abstract}
Façades, the first aesthetical feature of a building which distinguishes one building from another, have to fulfill the basic aspects like protection against fire and burglary, climatic influence and environmental pollution. Development in facades has made it more functional, providing designers with the flexibility to create high performance solutions, which are visually exciting, both internally and externally. This paper is the state-of-art discussing the types of glasses in facades, their applications, functional and strength requirements in tall buildings
\end{abstract}

Keywords: Facades, Failures, Stresses, Non-linear Analysis, Tall Buildings

\section{Introduction}

Structural Facades plays an essential role in science and building Industry. Glass is a material commonly used in facade systems. It is a material known for millennia and has been used in buildings for centuries. Nowadays it is being used as a structural material rather than a transparent infill within a supporting frame. The changing approach to the use of glass has been made possible by the improved quality of glass, development of the float glass and thermal strengthening (tempering) process and the availability of analysis tools. The use of glass to create large transparent screens, roofs and floors has been driven by the architectural desire to achieve lightness of construction, transparency and the availability of larger panes of glass.

Glass being a brittle building material is weak in tension because of its non-crystalline molecular structure. Glass balances the practical functions of thermal insulation, solar control, safety and security, acoustic insulation, fire protection etc. It has the failing that it is a brittle material but engineers are learning to design within the necessary safety parameters. A further limitation to the use of glass has been the ability to make structural connections. However, many proven solutions are now available.

For the design of facade systems in India, ASTM / Euro Codes are normally followed as Indian Codes do not address such information. This necessitates more study on the structural performance of glass panels for Indian conditions. In the proposed study, the glass panels with different end conditions, at different loadings and for different aspect ratio will be analysed which will help the designers. This paper is the state-of-art discussing the types of glasses in facades, their applications, functional and strength requirements in tall buildings.

\section{Types of Glasses in Facades}

The following are the types of glasses commonly used in building industry as facades (Ledbetter et al., 2006): Annealed Glass; Tempered or Toughened Glass; Heat Strengthened Glass; Reflective Glass and Laminated Glass.

\subsection{Annealed Glass:}

Annealed or float glass is glass that has been cooled gradually from a high temperature during manufacture to 
minimize residual stress. It allows the glass to be cut by scoring and snapping for required size. It is the most commonly available type of flat glass. Standard thicknesses of annealed glass in mm are 3, 4, 6, 8, 10, 12, 15 and 19. This glass is one of the weakest glass types and has a significant potential to break when subjected to over loads. On breakage, the glass tends to form sharp-edged, pointed shards which may cause piercing and cutting injuries. The post failure behaviour of the glass will be dominated by its lack of residual strength on breakage. The glass may not be able to resist loads potentially causing (i) full or partial collapse of the glass structure (ii) penetration of the glass structure and (iii) glass fragments or shards to fall when it is used at height. It is for these reasons that monolithic annealed glass is not used as a highly stressed structural glass.

Annealed glass is subject to stress corrosion cracking under long duration loads. This phenomenon is due to chemical corrosion at the tips of surface micro-cracks caused by the action of water, which elongate the crack. There is a threshold stress below which stress corrosion cracking is no longer a significant factor and this is taken as $7 \mathrm{~N} / \mathrm{mm}^{2}$.

Another phenomenon to which annealed glass is vulnerable is thermal shock. This causes cracking due to internal stresses resulting from temperature differences between different parts of the same sheet of glass. The critical temperature difference has been found to be $33^{\circ} \mathrm{C}$. The possibility of thermal shock is greatest where parts of the glass are in shadow, while other parts are exposed to direct sun (Wilson and Malishevi, 2005). Annealed glass can be processed to produce other glass types such as tempered, laminated and insulating.

The properties of annealed glass are:

$\begin{array}{ll}\text { Density (approximate) } & : 2.42-2.52 \mathrm{~g} / \mathrm{cm}^{3} \\ \text { Tensile strength } & : \text { N } 40 \mathrm{sq} \cdot \mathrm{mm} \\ \text { Compressive strength } & : 1000 \mathrm{~N} / \mathrm{sq} . \mathrm{mm} \\ \text { Modulus of elasticity } & : 70 \mathrm{GPa} \\ \text { Coefficient of linear expansion } & : 9 \times 10-6 \mathrm{~m} / \mathrm{m} \mathrm{K} \\ \text { Available thickness } & : 2 \mathrm{~mm}-19 \mathrm{~mm} \\ \text { Normally available sizes up to } & : 2440 \mathrm{~mm} \times 3660 \mathrm{~mm}\end{array}$

Annealed clear glass transmits most of the solar radiation or short wavelength energy, falling on it. This property of glass allows us to see through it and to use the light from the sun to illuminate tasks. The energy gain from the sun can also provide heat to a room. On the other hand, clear glass absorbs most of the infrared radiation (long wave radiation) emitted by people and interior building surfaces. However, most glazing materials are poor thermal insulators and the absorbed energy is readily conducted to the cold exterior winter world. As a consequence, windows tend to have high transmission in relation to insulated walls.

\subsection{Tempered or Toughened Glass:}

Tempered glass is an extremely strong glass which is heat treated to a uniform temperature of approximately $650^{\circ} \mathrm{C}$ and rapidly cooled to induce compressive stresses of $770 \mathrm{~kg} / \mathrm{m} 2$ to $1462 \mathrm{~kg} / \mathrm{m} 2$ on the surfaces and of the order of $680 \mathrm{~kg} / \mathrm{m} 2$ on the edges. Tempered or toughened glass gains its added strength from the compressed surfaces. However, if a deep scratch or an impact penetrates the surface, the glass will break into a number of small particles. The heat treatment process for tempered glass requires that all fabrication be completed prior to toughening. Drilling, grinding or sand blasting and edge cutting after toughening may result in glass breakage. The heat treatment process does not change the light transmission and solar radiant heat properties of the glass. In the event of breakage, toughened glass generally breaks into small, relatively blunt, glass fragments called dice. These fragments do not have sharp edges and are unlikely to cause deep cutting injuries. However, they may form blunt-edged clumps. These are less likely to cause piercing injuries than shards of annealed or heat-strengthened glass but may still cause injury.

Due to the inherent superior features of tempered glass like more strength, ability to withstand sudden impacts and breaking safely into small pieces, it is used as a safety glazing; applications where glass safety is needed is facades on higher floors with risk of falling glass.

\subsection{Heat Strengthened Glass:}

Heat strengthened glass is a type of tempered glass which has been strengthened thermally by inducing a surface compression of 422 to $658 \mathrm{~kg} / \mathrm{cm}^{2}$ as compared to a range of 770 to $1462 \mathrm{~kg} / \mathrm{cm}^{2}$ in case of fully tempered glass. In the manufacturing process, a permanent compressive surface stress and a permanent tensile internal stress are 
induced in the glass. The compressive surface stresses give the glass a bending strength higher than that of annealed glass and reduce the likelihood of glass failure.

Heat strengthening of glass is a separate process; heat strengthened glass is valued for its mechanical strength, which is twice that of normal annealed glass though half of fully tempered glass. With the exception of strength and breakage characteristics, heat strengthened glass retains the normal properties of annealed glass. Heat strengthened glass provides necessary resistance to thermal stress associated with high performance glazing materials such as tinted glass and reflective glass. It also provides necessary resistance to building heat when used as spandrel glass.

Heat Strengthened glass is suitable for spandrel and vision panels of curtain walls and structural glazing as they safeguards against thermal breakage. It is used for making laminated glass panels for safety combined with strength. It is used in complex glass combinations like double-glazing.

\subsection{Reflective Glass:}

A metallic coating is applied to one side of the glass in order to significantly increase the amount of reflection by the glass for both the visible and infra-red (light and heat) range of the electromagnetic spectrum. The reflective glass imparts a mirror like appearance to the exterior of buildings under most daylight conditions. Due to the coating of metal oxides on the glass, they are widely applied as an aesthetic product in buildings for its highly reflective surface and its wide palette of colours. It reduces heat gain and glare from the exterior and allows optimum visible light transmission to the interior. An exceptional property of solar reflective glass is that the coating of metal oxides on the glass can be achieved without affecting the transparency of the glass.

Reflective glass has increased aesthetic appearance and it gives enormous flexibility in designing the exterior due to availability of number of colours / shades. It facilitates energy savings through reduction in interior solar heat gain and cost reduction in the cost of heating and cooling systems. It also improves occupants comfort as interior temperature variations are less and easier to control and it reduces the air- conditioning load of the buildings. Reflective glass is used in office buildings, high-rise buildings at entrance, privacy windows, decorative walls, spandrel glazing, vertical and sloped glazing, solar control applications and building facades.

\subsection{Laminated Glass:}

Laminated glass is composed of two or more layers of glass with one or more layers of a transparent/ pigmented and specially treated plastic Polyvinyl Butyral [PVB] sandwiched between the glass layers. The glass panes (layers) can be either normal glass or tempered glass. When the glass is broken, fragments tend to adhere to the plastic $[\mathrm{PVB}]$ interlayer thereby reducing the risk of injury and helping to resist further damage by weather. The strength, breakage characteristics, and post failure behaviour of laminated glass are dependent upon the glass types, glass thicknesses, and interlayer types and thicknesses used in construction.

Laminated glass does not shatter like ordinary glass. It absorbs impact, resists penetration and remains intact even if broken, holding glass fragments in place and lowering the risk of injury. It resists intrusion because the interlayer continues to safeguard the building even after the glass itself is broken. It tends to resist impact. It can even resist bullets, heavy objects or small explosions. It is capable to stop flying debris and limit or avoid splintering on opposite side of the impact. It is an excellent barrier to noise. The shear damping performance of the plastic interlayer makes laminated glass an effective sound control product.

It retains its colour and strength for the life of the building and is as easily cleaned as any conventional glass. When exposed to heat, laminated glass breaks but stays in place longer. The risk of thermal breakage is avoided only when heat strengthened / tempered laminated glass is used.

Laminated glass is used in office buildings, hotels, restaurants, shopping malls, public walkways, hospitals, libraries, museums, churches, airport terminals, residences and apartment buildings, noise control applications, embassies, computer centers. High security places, for example, banks, teller and drive-through windows, ticket windows, gas stations, currency exchanges, armoured vehicles, jewellery shops and burglar resistant showcases. Other areas where laminated glass is used are: Curtain wall glazing, sloped glazing, skylights, glass roofs and floors, aquariums, safety glazing for partitions and security glazing for banks against bullets/ hand propelled objects.

There can be made the distinction in annealed glass (Float-glass) with a tensile strength of $45 \mathrm{MPa}$, heat strengthened glass with a tensile strength of $70 \mathrm{MPa}$ and thermally toughened glass with a tensile strength of 120 MPa (www.glassfiles.com). 


\section{Fire Safety Facades}

As architects develop new and leading edge creative curtain wall designs, it becomes more critical to consider the risk factors that can impact the building's overall level of fire safety (Connor, 2007). The risk of fire spread through articulated elements of the façade or vertically around the facade via the mechanism of flame leap, poses new concerns for the newest class of super high-rise structures. Horizontal projection above flames issuing from a window can be effective at reducing the flame exposure. The vertical exterior elements could have a negative impact by increasing the vertical projection of flames along a façade.

There are currently two basic ways to provide a code complying curtain wall design in fully sprinklered buildings. The most basic approach is the curtain wall to be supported directly on the structural floor slab edge, which precludes any gap or joint condition, given that the floor slab is continuous to or extends past the building envelope. The second approach is applicable when the curtain wall assembly is positioned just outside the edge of a fire rated floor system, such that a void space results between the floor system and the curtain wall assembly.

To prevent the interior spread of fire, International Building Code(2007) and the National Fire Protection Association's 2006 Building Construction and Safety Code (NFPA 5000) suggested that the void space at the slab edge be sealed with an approved material or Perimeter Fire Barrier systems.

The systems certified by Underwriters Laboratories (UL) which is the fire apparatus as per ASTM E2307 are measured in the following four aspects:

\subsection{F-Rating:}

An F-rating evaluates the most fundamental function of a perimeter fire barrier system. This is testing the ability of the perimeter fire barrier system to maintain fire resistance in the void space between the interior surface of the curtain wall assembly and the floor slab edge. The F-rating is expressed in hours (e.g. 2 hours) for comparison to the fire resistance rating of an associated floor assembly.

\subsection{T-Rating:}

T-rating evaluates the extent of temperature increase on the non-fire side of the perimeter fire barrier system. The temperature measurements are taken at a point $25.4 \mathrm{~mm}$ ( $1 \mathrm{in}$.) or less above the fill materials perimeter fire barrier system. T-ratings are typically in on the order of $0,1 / 4$ and $1 / 2$ hour.

\subsection{An Integrity Rating:}

This rating evaluates the temperature rise on the unexposed interior surface of the curtain wall assembly above the fill materials. This is intended to determine if fire can spread to a floor above through the curtain wall system and not just the fill material of the perimeter fire barrier system. Insulation ratings are typically in on the order of $0,1 / 4$ and $1 / 2$ hour.

\subsection{An Insulation Rating:}

This rating evaluates if there is any flame passage or surface flaming on the interior surface of the curtain wall assembly above the fill materials and in addition, the glazing above the fire exposed floor is monitored to determine when the glazing breaks. The intent of monitoring the glazing integrity is to identify how long in hours the curtain wall glazing will survive, resisting the fire leapfrog that has been observed to occur in multi-story buildings.

\section{Glass as Structural Material (Ledbetter et al., 2006)}

In modern façade, there is a tendency to maximise the transparency of building. One possibility might be to reduce the size of framing member by the use of tension structure (in which the facial glass is fixed to the glass fin by structural sealant). Another possibility might be to extend the use of glass to load carrying elements. When glass is used as the load carrying elements, it is usually in the form of glass fin in vertical or slightly sloped direction and glass beam in horizontal direction. Glass fins/beams are generally simply supported. Nowadays, glass fins of span longer than $10 \mathrm{~m}$ are commonly used. Even a glass wall specimen with glass fin of span upto $19 \mathrm{~m}$ is adopted.

The material properties of glass are similar to those of aluminum particularly when the glass is toughened and fully tempered (Table 1). The significant differences between glass and aluminum are as follows (i) the brittleness of the glass compared with the ductility of aluminium (ii) the resultant influence of fracture mechanics on the failure of glass and (iii) the time dependent failure stress of glass.

When building with glass it is always necessary to assume that failure of a sheet of glass may occur and post failure behaviour governs the use of glass as a structural material. The problems of brittleness of glass components may be overcome by 
- The use of laminated glass so that there is some residual strength provided by the unbroken layers of glass and/or the interlayer

- Using ductile interfaces at connections to avoid concentrated loads

- $\quad$ The provision of alternative load paths within a redundant structure

- $\quad$ Bonding glass to a frame to ensure retention of the glass and

- $\quad$ Using nets, meshes or other building features to catch, or break-up glass, which falls.

\section{Analysis of Glass facades}

The applied load causes lateral deflections often larger than the thickness of the lite inducing membrane stresses. Thin plates subjected to large deflections create a nonlinear interaction between the stresses due to membrane and bending action. Lite thickness, rectangular surface area, aspect ratio and the magnitude of the lateral load affect the interaction between the membrane and the bending stress. Linear models predict higher stresses than nonlinear models and consequently are not used for predicting glass strength.

The relationship between the maximum principal stress in glass lites associated with their design loads for a probability of breakage of 8 lites per 1,000 is given by Morse and Norville, 2010. The values for maximum principal stress for a constant probability of breakage vary as a function of lite thickness, surface area and aspect ratio, which is a result of the glass failure prediction model. Maximum principal stress is not constant for a single lite thickness for varying rectangular dimensions much less for all lite geometry combinations. A series of charts illustrates the trends in magnitude and location of the maximum principal stress as a function of lite thickness, aspect ratio, and surface area. The series of glazing configurations consisted of the 12 lite thicknesses from ASTM E1300-07 ranging from $2.5 \mathrm{~mm}$ to $21 \mathrm{~mm}$ and length to width combinations ranging from $50.8 \mathrm{~mm}$ to $5,080 \mathrm{~mm}$ in increments of $50.8 \mathrm{~mm}$. The minimum allowable thicknesses for each nominal lite thickness are used for the calculations. Due to symmetry, only long to short dimension combinations having aspect ratios of 1.0 or greater were considered in this analysis, resulting in 5,050 glazing configurations per lite thickness.

The allowable stress design is generally defined as limiting stresses developed in the material due to a design load must be less than the elastic limit and subsequently a design factor ensures the stresses remain well below the elastic limit.A design factor would be selected to further reduce the allowable stress for design purposes. Allowable stress design method is not much complex method but that would not account for several factors known to affect window glass strength including lite thickness, surface area, glass surface condition, aspect ratio, and load duration.

The possibility of reproducing the behaviour of laminated glass is dependent on the exact knowledge of the viscous behaviour of the interlayer between the glass sheets. This is not supplied by the producer satisfactorily and it has, therefore, to be determined with shear tests. A standard practice for determining the shear behavior of interlayer within laminated glass is necessary, and the design rules have to take into account for the results of such tests. On the contrary, national rules dealing with glass structures, among which, for example, the ASTM E1300-07e1 (ASTM 2007) focus on specific load and constraint conditions, and on not specified PVB ( Polyvinyl Butyral ) interlayer; on the other hand, French rules (CSTB 1996, 1999) apply to wider constraint conditions (four-point supply condition ), but cannot take into consideration the kind of interlayer plastics (Bati et al., 2010).

\subsection{Iterative analysis of nonlinear glass plates (Vallabhan, 1983):}

The material of the glass plate is assumed to be elastic with small strains, thus the problem becomes a geometrically nonlinear one where the deformation of the plate in its own plane, called "membrane behavior" must be analyzed in addition to the bending behavior of the plate in the lateral direction. The glass plate is assumed to be simply supported without any restraint for in plane displacement at the supports. Von Karman's theory of Plates is used to represent the large deflection- small strain type behavior of the plates. Since the problem is nonlinear, an iterative technique is used. A simple finite difference model for the nonlinear analysis of rectangular glass plates is considered. An efficient scheme is developed to accelerate the convergence of the iterative solution. Results compared well with other known solutions. The main advantages of this method are (i) the model gives direct solution for any pressure without reference to previous loadings (ii) usual errors creeping into the solutions step-by-step incremental procedures are avoided and (iii) the method is simple and the computation time is less for a good satisfactory solution.

\subsection{Interactive nonlinear analysis of insulating glass units (Vallabhan and Chou, 1986):}

An insulating glass (IG) unit consists of two glass plates, normally rectangular, placed parallel to each other using a spacer and sealed with a sealant to an extent that the whole unit is considered air tight after manufacture. 
Desiccants are used inside the spacer to absorb any moisture in the air trapped inside. A theoretical model is created to analysis the structural behavior of the Insulating glass units when subjected to lateral pressures induced by wind loads and variations of temperatures. The sharing of the loads between the two plates was analyzed using a nonlinear plate analysis theory.

It is assumed that the windward glass plate is subjected to a uniform pressure, which when it deflects, compresses the inside air, inturn the compressed air applies pressure on both plates. The change in volume of the air within the sealed airspace due to the induced inside pressure is calculated using Boyle's ideal gas law. Since the behaviour of the plates and the change in volume of the air inside are both nonlinear functions of pressure, an iterative scheme has to be employed to equilibrate the system.

Interactive analysis has been done for (i) constant temperature across the IG unit and (ii) variable temperature across the IG unit. For an IG unit with equal plate thicknesses, the windward plate assumes a slightly larger percentage of lateral pressure than the leeward plate. This percentage grows as the lateral load and/or the size of the spacer increases.

For an IG unit with unequal plate thicknesses, the thicker plate always shares a higher percentage of the load. The study of the effects of temperature difference between installation and service shows that, for a wide range of temperature differences, internal pressures that are produced are small and the lateral pressure increases with the decrease in temperature difference.

\section{Glass Plate Failure}

Glass plates are thin rectangular plates with continuous edge supports. The plate supports are designed to allow the plate edges to rotate and to slip in the plane of the plate, but to limit the lateral displacement of the plate. The design load for a typical glass plate is a uniform lateral load representative of wind forces. Glass plates normally experience lateral deflections which are in excess of their thicknesses when exposed to design loads. When a plate undergoes deflection of this magnitude the middle surface of the plate stretches, resulting in the introduction of membrane stresses.

The surfaces of glass plates are covered with minute flaws of varying geometries and orientations. These flaws result from the manufacturing process and subsequent exposure. When a glass plate is loaded, the surface flaws interact with surface tensile stresses and cause large local stress concentrations.

Glass failure is of concern as it may impair or lead to the failure of the structure and allow glass to fall and injure people.Glass plate failure occurs when the local stress associated with one of the surface flaws becomes large enough to initiate fracture. The critical flaw is the surface flaw which initiates the fracture. The magnitude of the stress-raising potential of a particular flaw depends upon its geometry and orientation, with respect to the nominal tensile stress field. There is considerable variability associated with the stress-raising characteristics of glass plate surface flaws. Therefore, the location of the flaw which initiates glass plate failure does not necessarily correspond to the point of maximum stress. Glass failure may be due to impact or thermal stress.

\subsection{Impact:}

Failure is caused by a sudden localized contact with a force that is sufficient to overcome the strength of the glass. This contact force may be caused by contact with a hard body or a soft body and may be caused accidentally, deliberately or by the forces of nature. Hard body impacts are caused by stones and larger objects that may be thrown, dropped or carried by extreme winds. Soft body impacts are caused by human bodies and objects such as footballs.

\subsection{Thermal Stress:}

Failure is caused by a temperature difference between the center and edge of a glass pane, which induces stresses within the glass. The centre of the glass is heated by sunlight, and the edge of the glass remains relatively cold (under the shade of frame). This results in the expansion of the centre of the glass which produces a tensile stress on the glass edges and causes failure. The other common causes of glass failure are inclusions, malicious damage, small projections, scratching, deliberate impact, failure of heat-treated glass and blast.

A glass failure prediction model proposed by Season and Morgan, 1984 relates the probability of failure of glass to surface flaw characteristics and induced stresses. The glass-failure-prediction model is based on the assumption that the strength of glass is controlled by the interaction of surface tensile stresses and stress raising surface flaws.

During strong windstorms, various cladding materials (glazing panels) are often damaged. Damage to windows and glazing has generally been outstanding in both residential structures and high-rise buildings. Although 
windborne debris has been considered as a significant factor of window damage, there is a potential of window glass breakage due to fluctuating wind pressures as well (Eri Iizumi and Kopp,2005).

Simple loading test, ramp loading test and saw-tooth loading test have been conducted to understand the behaviour of glass plate under fluctuating wind loads. Test results of full-scale glass plate breakage test under ramp loading and saw-tooth loading were presented with a comparision of numerical simulation results.

\section{Glass Design Procedure}

A simplified window glass design procedure (SWGDP) as an alternative to the comprehensive window glass design procedure is described in ASTM E 1300, "Standard practice for determining the load resistance of glass in buildings" (Norville et al., 2000).

Simplification of the ASTM E 1300-98 procedure is based on four principal observations (i) Most glass design situations involve monolithic glass, symmetrical insulating glass units or laminated glass units. That means the glass units are made up of same thickness of glass with same type (ii) Most glass design situations involve rectangular dimensions with aspect ratios of 2:1 or less and glass component thicknesses that prove to be relatively thin (iii) Wind loads (for vertical glazing) and snow loads (for sloped glazing) govern essentially all architectural glazing designs. Dead loads do not exist for vertical glazing and are usually small in sloped glazing, causing negligible effects and (iv)Simple graphs incorporating glass lite geometry can be adequate enough, since ASTM E 1300 specifies no deflection limits, describe relationships for center deflections versus lateral load.

The percentage of the applied lateral loading that each lite carries depends upon the magnitude of the lateral load, relative thickness of the glass lites, absolute stiffness of the glass lites, width of the air space and aspect ratio of the IG unit. ASTM E 1300-98 captures these relationships by presenting approximate load-share factors that vary with aspect ratio, flexibility factors and relative glass lite thickness.

French standards simplify the design of laminated glass introducing an equivalent thickness for the evaluation of load bearing capacity of the laminated plate, that takes into account, the number and thicknessof glass plies, but cannot account for the kind of interlayer, that is, for its elastic properties, and for the ambient conditions ( moisture and temperature) (CSTB 1996, 1999). On the other hand, American standards (ASTM E1300-07e1) (ASTM 2007) provide guidelines for the calculation of laminated glass elements of rectangular shape with continuous lateral support along one, two, three or four edges, simply supported; in so doing, they do not allow the design freedom required for architectural purposes(S. Briccoli Bati et al., 2010).

LG beams may behave far from monolithic. So, the monolithic equivalency model is dangerous, and it cannot be assumed for design purpose, since its implementation would result in unsafe design and use of LG, which often would lead to failure of the LG at the design load (Paolo Foraboschi., 2006).

When a glass design situation meets the following three conditions, a designer can use the simple design procedure consisting of the single chart and table of strength adjustment factors as per ASTM E 1300-98. (i) its aspect ratio (length: width) is 2:1 or less, (ii) it comprises monolithic or laminated glass with symmetrical plies (iii) if the product is an insulating glass unit, its construction is symmetrical with thin lites.

\section{Performance Factors of Windows}

The building envelope protects the inhabitants from the elements, keeps noise and intruders out and controls heat loss and gain. Window performance factors (Brown and Ruberg, 2005) includes the light transmission properties of windows as well as those that are applicable to opaque walls. They can be divided into three major groups, as follows:

\subsection{Energy Filter:}

Energy can be selectively reflected or transmitted by choosing different types of glazing or the transparent portion of a window. This transparent portion acts as Energy Filters.

\subsection{Light transmission and Access to view:}

The primary function of a window has to provide the building occupants with light and view. Day lighting is the use of natural light to illuminate tasks. Daylight and view combined can lead to pleasant interior spaces. It can reduce electric lighting and cooling loads in large commercial buildings. Heavily tinted and reflective glazings transmit as little as $8 \%$. Both the amount of natural light available in a room, and its colour, can be affected by the choice of glazing. Impurities and thickness both increase the absorption of light by glass. Table 2 provides a range of light transmission values for various glazing materials. Fig. 1 shows that sunlight striking window can be transmitted, reflected or absorbed. 


\subsection{Thermal performance:}

It involves both heat transmission through the window and surface temperature of the window. Surface temperature performance relates to moisture condensation and its effect on the durability of the system. Surface temperature performance of the frame can be improved by constructing the frame with low conductivity materials or by using thermal breaks between inside and outside frame surfaces.

Heat transmission includes heat loss from the heated interior to the colder exterior and heat gain by solar radiation. Both aspects of thermal performance can have an impact on the thermal comfort of the space.Thermal transmittance, or U-value, is normally used to rate the heat transmission of windows. The amount of heat transferred through a window is directly proportional to the U-value of the window.

The thermal resistance of the glazing system can be increased significantly by enclosing one or more air spaces between panes of glass, by the use of low emissivity coatings, or the use of low conductivity gases in the spaces between lights. Risk of thermal breakage is high: e.g. south and west facing facades using reflective glass.

\subsection{Sound transmission:}

Noise is a frequency dependent phenomenon. Windows can transmit noise by mechanical vibration and through air leaks associated with the window. It is governed by the mass and stiffness of the window.The practical noise control measures are limited by the properties of glass and other glazing materials and the characteristics of window assemblies. As sound is an air-borne phenomenon, noise control measures can also be strongly affected by the airtightness of the window.

\subsection{The Window as Part of the Building Envelope:}

Window is to be designed to withstand the structural stresses imposed on the building envelope. The performance of windows under fire conditions must be recognized and it has to function as the air, vapour and weather barriers of the building.

Glass is a brittle material and the structural failure of glass can be quite sudden and dangerous. While the theoretical strength of glass is quite high in both tension and compression, this strength is not achieved in practice because of surface and edge flaws in the glass sheet.

\subsection{Stresses on the glass and frame:}

Tall buildings, with irregular shapes, are subjected to complex wind pressures at building corners and along the faces. Wind tunnel tests are the most reliable method of determining the pressure variation on the facade of commercial buildings for design purposes. Thermal stresses, leading to thermal breakage, is source of concern in the design of glazing systems. They are caused by a difference of temperature between the edges and middle of a glass pane. The condition of the edge of the glass pane will strongly influence the breaking stress of the pane.

The following situations should be avoided to reduce the potential for thermal breakage: (i) low thermal resistance connections to heat sinks such as masonry which can cool the edge of the glazing (ii) deep reveals that cast shadows along the edge and allow solar gain on the middle of the glazing (iii) reflective coatings facing the air space of a double glazed unit or an inner light of heat absorbing glass and (iv) air-conditioning units blowing air directly on the glazing.

\section{Conclusions}

Glass is now being used as an acceptable structural material, although only few codes or standards exist to govern the design and construction of structures with glass. In the present paper the types of glasses, its properties and applications, glass failure, design procedure and structural use of glass are discussed. As glass can be used safely to create roofs, walls, balustrades, floors, stairs, and bridges and to create architectural structures with transparency and lightness, it necessitates more research work to be carried out in this thrust area.

\section{References}

Australian Standard, AS 1288 - 1994. Glass in buildings - Selection and installation.

ASTM E 1300-98 Standard practice for determining load resistance of glass in buildings.

ASTMC 1036: C 162 Terminologies of Glass and Glass Products.

British Standard, BS 6262. Code of practice for glazing for buildings.

C. V. Girija Vallabhan,1 M. ASCE. (1983). C ASCE. Iterative Analysis Of Nonlinear Glass Plates. Journal of Structural Engineering, vol. 109, No. 2, Proc. No. 17739. 
C.V. Girija Vallabhan, M. ASCE and Gee David Chou. (1986). CASCE, Interactive Nonlinear Analysis of Insulating Glass Units. Journal of Structural Engineering, Vol. 112, No.0006-1313 Paper No. 20674.

Dr.-Ing. Barbara Siebert. Modern Facades of tall buildings. from www.glassfiles.com.

H. Scott Norville,P.E., Member, ASCE, and Joseph E. Minor, P.E., Fellow. (2000). Simplified Window Glass Design Procedure. Journal of Architectural Engineering, Vol. 6, No. 4,pp 0105-0115.Paper No. 16863.

IS 1382. (1981). Glossary of terms related to glass \& glassware (first revision) Indian Standard codes of Practice for Glazing, New Delhi.

IS 10439. (1983). Indian Standard, Code of practice for patent glazing Indian Standard codes of Practice for Glazing, New Delhi.

IS 875. (1987). Indian Standard, Code of Practice for Glazing for design loads (other than earthquake) for buildings \& structures, part 3: wind loads Indian Standard codes of Practice for Glazing, New Delhi.

IS 2835. (1987). Specification for flat transparent sheet glass Indian Standard codes of Practice for Glazing, New Delhi.

IS 3548. (1988). Indian Standard, Code of practice for glazing in buildings Indian Standard codes of Practice for Glazing, New Delhi.

IS 2553 (1990). Safety glass - specification (Part 1) Indian Standard codes of Practice for Glazing, New Delhi.

IS 5437. (1994). Figured, rolled and wired glass - specification Indian Standard codes of Practice for Glazing, New Delhi.

Iizumi, E., Kopp G.A.. (2008). Behaviour of glass plates under pressure loading. 1st American Association for Wind Engineering (AAWE) - Workshop, AAWE, Colorado, USA.

Paolo Foraboschi. (2006). CASCE, Behavior and Failure Strength of Laminated Glass Beams. Journal of Engineering Mechanics, Vol. 133, No. 12, December 1, 2007.

Philip WILSON, Gennady Vasilchenko-Malishev. (2006). The Design And Construction Of All Glass Structures, Malishev Wilson Engineers, 96a Inderwick Road, London N8 9JY.

Stephen R. Ledbetter., Andrew R. Walker and Alan P. Keiller. (2006). CASCE, Structural Use Of Glass, Journal of Architectural Engineering, Vol. 12, No. 3,pp. 137-149.

Stephen M. Morse, A.M.ASCE1; and H. Scott Norville, P.E., M.ASCE. (2010). CASCE, Relationship Between Probability of Breakage to Maximum Principal Stresses in Window Glass. Journal of Architectural Engineering, Vol. 16, No. 1 pp-20-28.

S. Briccoli Bati, G. Ranocchiai, C. Reale, and L. Rovero. (2010). Time-Dependent Behavior of Laminated Glass. Journal of Materials in Civil Engineering, Vol. 22, No. 4, April 1, 2010. CASCE, ISSN 899-1561/ 2010/4-389-396/

W. Lynn Season1 and James R. Morgan / M. ASCE. (1984). CASCE Glass Failure Prediction Model. Journal of Structural Engineering, Vol. 110, No. 2, Paper No. 18586.

W.C.Brown and K Ruberg. (15th Nov 2005). Window Performance Factors-National Research council, Canada. 
Table 1. Properties of glass and aluminium

\begin{tabular}{|l|c|c|c|}
\hline & Annealed glass & $\begin{array}{c}\text { Toughened } \\
\text { Glass/fully Tempered }\end{array}$ & Aluminium \\
\hline Strength $\left(\mathrm{N} / \mathrm{mm}^{2}\right)$ & $7-28$ & $59-150$ & 130 \\
\hline Young's modulus $\left(\mathrm{kN} / \mathrm{mm}^{2}\right)$ & 70 & 70 & 70 \\
\hline Density $\left(\mathrm{kg} / \mathrm{m}^{3}\right)$ & 2.4 & 2.4 & 2.6 \\
\hline $\begin{array}{l}\text { Thermal Coefficient of } \\
\text { Expansion }\left(\mathrm{K}^{-1}\right)\end{array}$ & $8.8 \times 10^{-6}$ & $8.8 \times 10^{-6}$ & $23 \times 10^{-6}$ \\
\hline Poisson's Ratio & 0.22 & 0.22 & 0.34 \\
\hline Source: Data from “STRUCTURAL USE OF GLASS”, 2006 \\
\hline
\end{tabular}

Table 2. Light transmission characteristics

\begin{tabular}{|l|c|}
\hline \multicolumn{1}{|c|}{ Description } & Visible \\
\hline Float, single strength clear glass & $91 \%$ \\
\hline Double strength clear glass & $90 \%$ \\
\hline Float, clear - $2.35 \mathrm{~mm}$ thick & $91 \%$ \\
\hline $6.35 \mathrm{~mm}$ thick & $89 \%$ \\
\hline $19.05 \mathrm{~mm}$ thick & $83 \%$ \\
\hline Float, clear mirror & $89 \%$ \\
\hline Tinted blue-green & $75 \%$ \\
\hline
\end{tabular}

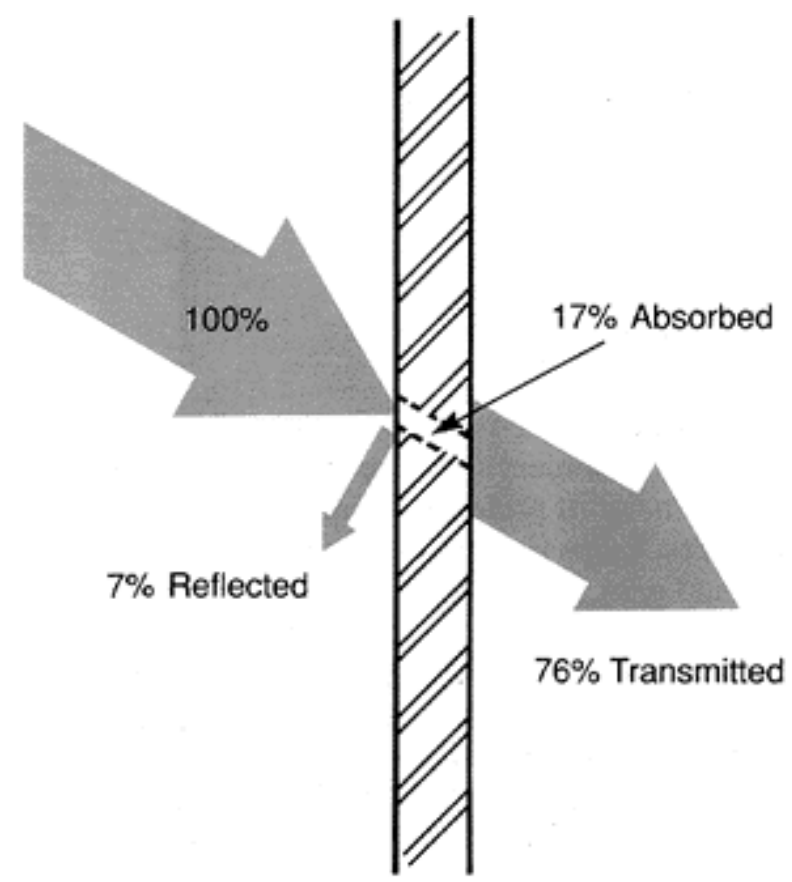

Figure 1. Sunlight striking window can be transmitted, reflected or absorbed 